\title{
Pengenalan Sistem Informasi Akuntansi pada Siswa SMK Nufa Citra Mandiri Kota Depok
}

\author{
${ }^{1 *}$ Tsarina Zenabia, ${ }^{2}$ Putri Wulandari, ${ }^{3}$ Alyssa Risthi, ${ }^{4}$ Dian Novianti, ${ }^{5}$ Diantia Amendy \\ Universitas Pamulang, Tangerang Selatan, Indonesia \\ *dosen02502@unpam.ac.id
}

\begin{abstract}
Abstrak
Pengabdian Kepada Masyarakat (PKM) dengan judul "Pengenalan Sistem Informasi Akuntansi Pada Siswa SMK NUFA Citra Mandiri Jurusan Tehnik Komputer Jaringan” ini bertujuan agar para siswa jurusan tehnik komputer jaringan memiliki pengetahuan yang lebih mendalam terkait pembuatan program dan jaringan berbasis data system informasi akuntansi. Kegiatan PKM dilaksanakan oleh para dosen yang tergabung dalam Program Studi S1 Akuntansi. Disamping melibatkan para siswa, PKM juga dihadiri oleh guru mata pelajaran komputer, wakil kepala kurikulum dan juga Kepala Sekolah. Hasil Pelaksanaan PKM yang dilakukan tanggal 26 November 2021 sampai dengan 28 November 2021 adalah para siswa memahami apa itu system informasi akuntansi sehingga mampu merancang bangun sebuah aplikasi computer dan jaringan berbasis system infromasi akuntansi. Respon para peserta terutama Kepala Sekolah dan para guru sangat baik. Kepala Sekolah juga mengharapkan agar kegiatan PKM kedepannya dapat dilakukan secara berkesinambungan, agar para siswa SMK jurusan tehnik komputer jaringan memperoleh referensi keilmuan tambahan terkait sistem informasi akuntansi yang dapat diaplikasikan kedalam sebuah program komputer dan instalasi jaringan dengan berbasis data/ informasi akuntansi.
\end{abstract}

Kata Kunci: Sekolah Kejuruan, Tehnik Komputer Jaringan, Sistem Informasi Akuntansi

\begin{abstract}
Abstrak
Community Service (PKM) with the title "Introduction to Accounting Information Systems for Students of SMK NUFA Citra Mandiri, Department of Network Computer Engineering" aims to make students majoring in computer network engineering have deeper knowledge related to making programs and networks based on accounting information system data. PKM activities are carried out by lecturers who are members of the Accounting S1 Study Program. Besides involving students, PKM was also attended by computer subject teachers, deputy head of curriculum and also the principal. The results of the PKM implementation carried out from November 26, 2021 to November 28, 2021, are that students understand what an accounting information system is so that they are able to design a computer application and network based on an accounting information system. The responses of the participants, especially the principal and teachers, were very good. The principal also hopes that future PKM activities can be carried out on an ongoing basis, so that vocational students majoring in network computer engineering obtain additional scientific references related to accounting information systems that can be applied to a computer program and network installation based on data/accounting information.

Keywords: Vocational School, Network Computer Engineering, Accounting Information System
\end{abstract}

\section{PENDAHULUAN}

Menurut visi dan misi Kementerian Pendidikan dan Kebudayaan (Kemendikbud) lulusan Sekolah Menengah Kejuruan (SMK) diharapkan memiliki keahlian, ketrampilan dan kebersaingan sehingga siap terjun ke dunia kerja. Untuk mencapai visi dan misi tersebut diperlukan unsurunsur pokok yang terdiri dari program keahlian/ jurusan, buku dan bahan ajar yang digunakan para siswa dalam kegiatan belajar agar lebih mudah memahami dan mengerti ilmu pengetahuan yang diajarkan, prasarana dan sarana (infrastruktur) yang mendukung proses belajar, daya minat masyarakat dan satu hal lagi yang menjadi dasar peningkatan mutu Sekolah Menengah Kejuruan adalah ketersediaan guru atau pengajar yang sesuai dengan bidang kejuruan (memiliki kompetensi / keahlian). Menurut Mulyadi, dkk (2010) untuk memenuhi unsur-unsur pokok diatas perlu dilakukan pemetaan secara berkala terhadap sekolah kejuruan. Sejak tahun 2005 Direktorat Pengembangan Sekolah Menengah Kejuruan (PSMK) mencanangkan program nasional secara besar-besaran dengan skenario pengembangan jumlah sisiwa SMK dan pengurangan jumlah 
siswa SMA dengan skema 70:30. http://jurnal.upi.edu/invotec/edition/46/vol.-vi-no.-17agustus-2010.

Untuk mewujudkan salah satu unsur pokok yaitu ketersediaan guru/ pengajar yang memiliki kompetensi bidang kejuruan, sertra pengayaaan materi pembelajaran, maka para dosen yang tergabung dalam civitas akademika Universitas Pamulang fakultas Ekonomi dan Bisnis mengadakan kegiatan Pengabdian Kepada Masyarakat (PKM) di sekolah kejuruan. Kegiatan Pengabdian Kepada Masyarakat (PKM) diselenggarakan di SMK Nufa Citra Mandiri, Sawangan, dan bidang pengabdian yang diambil dalam kegiatan PKM yaitu Tehnik Komputer dan Jaringan. Dipilihnya jurusan ini karena bidang Tehnik Komputer dan Jaringan merupakan bidang / jurusan yang banyak diminati para siswa karena prospek masa depan yang menjanjikan seiring berkembangnya tehnologi komputer. Dalam kegiatan PKM ini para siswa jurusan tehnik komputer jaringan akan diberikan pengenalan sistem informasi akuntansi (SIA) yang akan diselaraskan dengan kebutuhan siswa SMK terkait rancang bangun aplikasi sistem informasi akuntansi.

\section{Tehnologi Informasi}

Menurut Martin (1999) dalam Husaini 2017, tehnologi informasi tidak hanya terbatas pada teknologi komputer (perangkat keras dan perangkat lunak) yang akan digunakan untuk memproses dan menyimpan informasi, melainkan juga mencakup teknologi komunikasi untuk mengirim/menyebarkan informasi.

Berdasarkan dua definisi di atas, dapat disimpulkan bahwa teknologi informasi secara sederhana dapat dipandang sebagai ilmu yang diperlukan untuk mengelola/mengatur informasi agar informasi tersebut dapat secara mudah dicari atau ditemukan kembali. Sementara dalam pelaksanaannya untuk dapat mengelola informasi tersebut dengan baik, cepat, dan efektif, maka diperlukan teknologi komputer sebagai pengolah informasi dan teknologi informasi sebagai penyampai informasi jarak jauh.

\section{Tehnologi Komputer}

Tehnologi computer telah dipergunakan sejak abad ke - 19 dan saat ini sudah memasuki generasi kelima sejak tahun 2001. https://id.wikipedia.org/wiki/Sejarah komputer. (diakses 212-2021.15.56). Tehnologi computer berkembang seiring dengan berkembangnya tehnologi informasi dimana memudahkan para pengguna berkomunikasi sehingga tempat, waktu dan jarak bukan lagi menjadi kendala. (Husaini:2017).

Komputer yang dikenal saat ini adalah hasil pengembangan teknologi elektronika dan informatika terdiri dari CPU (Central Processing Unit) dan memori, CPU berfungsi untuk memproses perintah yang diberikan oleh pengguna komputer, mengelolanya bersama data-data yang ada di komputer. Unit atau peranti pemprosesan juga akan berkomunikasi dengan piranti input, output dan storage untuk melaksanakan instruksi yang saling terkait. (Fery:2015)

Di era globalisasi komputer memegang peranan penting untuk dapat memudahkan pekerjaan dan menyelesaikan berbagai masalah yang ada, mulai dari organisasi pemerintahan, organisasi swasta, perusahaan bisnis - retail, pabrikan, perbankan dan juga pendidikan. Sebagai contoh saat ini tehnologi komputer tidak hanya mempermudah para siswa belajar ataupun membuat laporan dalam bentuk tulisan (word) ataupun angka-angka (excel) namun tehologi komputer sudah menjadi bagian dari kurikulum/ mata pelajaran terutama sekolah kejuruan.

http://reportase.umy.ac.id/pengenalan-teknologi-komputer/ (diakses 30 November 2021, 18.30).

Menurut Husaini (2014), untuk memanfaatkan teknologi informasi dalam proses pendidikan, perlu dikembangkan perancangan dan membuat aplikasi database pada kurikulum, materi pembelajaran, merancang dan membuat aplikasi pembelajaran berbasis portal, web, multimedia interaktif yang terdiri atas aplikasi tutorial dan learning tool, pemanfaatan TV edukasi sebagai materi pengayaan. 


\section{SIA Terintegrasi Tehnologi Komputer}

Menurut Fery (2015) Sistem informasi terintegrasi dengan tehnologi computer ketika suatu komponen organisasi yang mengumpulkan, mengklasifikasikan, mengolah, menganalisa dan mengkomunikasikan informasi finansial dan pengambilan keputusan yang relevan bagi pihak luar perusahaan dan pihak ekstern dengan menggunakan tehnologi informasi komputer. Menurut Wilkinson pada Sofia:2018, Sistem informasi akuntansi merupakan suatu kerangka pengkordinasian sumber daya (data, meterials, equipment, suppliers, personal, and funds) untuk mengkonversi input berupa data ekonomik menjadi keluaran berupa informasi keuangan yang digunakan untuk melaksanakan kegiatan suatu entitas dan menyediakan informasi akuntansi bagi pihak-pihak yang berkepentingan. Dalam upaya meningkatkan kualitas pembelajaran dan pemenuhan kebutuhan industry dalam penggunaan pencatatan sisitem informasi akuntansi maka perlu meningkatkan kualitas pembelajaran siswa SMK jurusan tehnik computer dan jaringan dalam bidang system informasi akuntansi.

Pengenalan system informasi akuntansi terkait definisi akuntansi, fungsi akuntansi, siklus akuntansi, bagan alur data dan dokumen transaksi diberikan kepada siswa - siswai SMK, khususnya jurusan tehnik computer dan jaringan diharapkan para siswa mendapatkan gambaran dan referensi keilmuan dalam membuat aplikasi dan jaringan computer berbasis system informasi akuntansi.

Jurusan tehnik computer dan jaringan diharapkan mampu menginstal operating system (OS), membuat jaringan local area network (LAN) dan membuat aplikasi WEB berkembang merakit/ membuat software berbasisi sisitem infromasi akuntansi yang dibutuhkan oleh perusahaan/ industry.

Perkembangan tehnologi computer dan tehnologi informasi harus dibarengi dengan peningkatan keahlian dari sumberdaya manusia yang menggunakannya. Untuk mempersiapkan sumber daya manusia yang memiliki kompetensi dan keahlian dalam bidang tehnologi computer dan tehnologi informasi maka perlu dipersiapkan sedini mungkin.

Kompetensi atau keahlian para siswa terutama jurusan tehnik komputer dan jaringan harus diperkaya dengan sistem informasi akuntansi. Sistem informasi akuntansi banyak dibutuhkan pada perusahaan/ industri, baik industri kecil, menengah dan besar (Yohana:2019). Sistem informasi akuntansi menghasilkan laporan keuangan yang dibutuhkan oleh para manajer perusahaan dan para pengambil keputusan bisnis. Kebutuhan akan laporan keuangan hanya dapat diperoleh dengan cara mengumpulkan, mengklasifikasikan, dan mencatat data/ transaksi akuntansi kedalam 2 sistem yaitu: sistem manual dan sistem komputer (Hermaliani:2016).

Akuntansi adalah suatu aktivitas dalam mengidentfikasikan, mengukur, mengklasifikasi dan mengikhtisarkan sebuah transaksi ekonomi atau kejadian yang dapat menghasilkan data kuantitatif terutama yang bersifat keuangan yang dipergunakan dalam pengambilan keputusan (Harahap:2011). Berdasarkan pengertian akuntansi tersebut maka akuntansi tidak akan terlepas dari perhitungan angka atau pun arus uang keluar dan masuk. Hal ini menuntut orang yang berkecimpung di dunia akuntansi harus memiliki kemampuan yang baik dalam hal perhitungan. Pada waktu dulu, perhitungan akuntansi dilakukan dengan cara manual. Tetapi pada dewasa ini telah banyak alat bantu yang diciptakan untuk melakukan perhitungan akuntansi, ada yang berupa software dan ada juga yang berupa hardware (Sinaga dkk:2021).

\section{METODE PELAKSANAAN}

Metode pelaksanaan pengabdian kepada masyarakat ini diawali dengan melakukan studi pustaka tentang sejauh mana SIA dapat diberikan kepada siswa SMK. Survey peninjauan lapangan dan koordinasi dengan sekolah serta perolehan izin untuk mengadakan kegiatan PKM. Melakukan persiapan alat dan materi yang akan diberikan kepada peserta untuk mempermudah mereka dalam menerima informasi. Menentukan waktu pelaksanaan dan lamanya kegiatan pengabdian bersama-sama dengan tim pelaksana. Metode kegiatan pengabdian dilanjutkan dengan metode ceramah, tutorial, dan diskusi sesuai materi yang telah dipilih. Pemanfaatan laptop dan Liquid Crystal Display (LCD) membantu peserta pelatihan lebih mudah memahami dan mengingat materi pelatihan yang relatif cukup banyak dengan waktu pelatihan yang terbatas. Diakhir diskusi para dosen menambahkan aktivitas game tanya jawab kepada para peserta. 


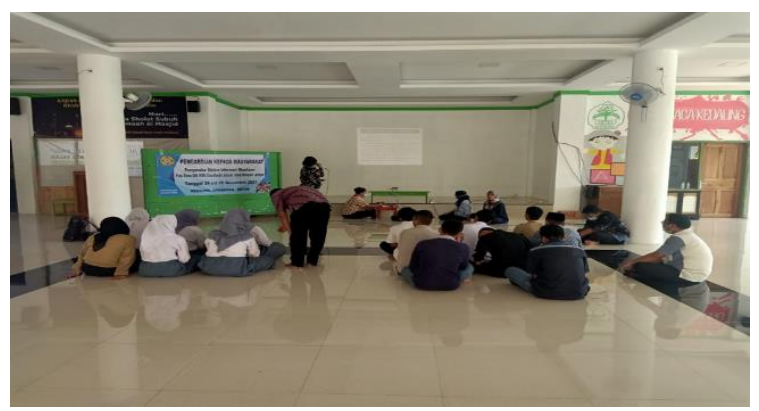

Gambar 1. Pelaksanaan Kegiatan

\section{HASIL DAN PEMBAHASAN}

PKM diselengarakan di Sekolah Menengah Kejuruan (SMK) NUFA Citra Mandiri, kelurahan Kedaung, kecamatan Sawangan, kota Depok. PKM dilaksanakan dari tanggal 26 November 2021 - 28 November 2021. Tujuan acara ini adalah untuk memberikan pemahaman dan pengenalan system infromasi akuntansi pada siswa SMK. Kegiatan pengenalan SIA ini diikuti kurang lebih 20 orang siswa, 1 guru mata pelajaran computer dan jaringan yaitu Bapak Sopari, 1 guru wakil bidang kurikulum yaitu Bapak Khairuddin dan Bapak Abdurohim selaku Kepala Sekolah serta para dosen Universitas Pamulang program studi S1-Akuntansi yang tergabung dalam tim pelaksanaan kegiatan PKM.

Peserta mengikuti pemaparan dari pemateri dengan seksama dan untuk menarik minat belajar para siswa pada saat sesi tanya jawab 7 peserta yang mampu menjawab pertanyaan pemateri mendapatkan pulsa gratis sebesar Rp. 25.000 sampai dengan Rp. 32.000. Adapun pemberian pulsa ini bertujuan untuk memberikan semangat kepada para siswa dalam mengikuti materi pembelajaran namun juga merupakan dukungan para dosen agar para siswa dapat memanfaatkan pulsa gratis tersebut untuk mengikuti pembelajaran secara daring dimasa pandemic covid 19.

Melihat kondisi geografis SMK NUFA Citra Mandiri yang terletak pada kelurahan Kedaung, kecamatan Sawangan kota Depok berdekatan dengan perumahan kelas menengah sampai atas dan didukung dengan akses jalan raya, hal ini menciptakan peluang untuk mendapatkan siswa atau calon siswa belajar. Akses nya dapat ditempuh dari segala arah, yaitu: sebelah barat terdapat jalan raya Jakarta-Bogor, sebelah timur terdapat perumahan Grand Osaka 5, sebelah utara terdapat perumahan Bukit Pesona Kedaung dan di sebelah Selatan terdapat perumahan Victoria Lake, serta disebelah tenggara terdapat perumahan Green Valley Cinangka, Sawangan. Pemanfaatan social media sebagai perantara pemasaran baik dari grup whats app, facebook dan youtube sangatlah memungkinkan untuk sekolah dalam meningkatkan jumlah siswa belajar. Disamping itu Yayasan Nurul Falah yang menaungi SMK NUFA Citra Mandiri sudah memiliki sarana dan prasarana yang memadai, yaitu: ruang kelas, ruang laboratorium dan ruang perpustakaan serta masjid, kantin dan toko alat tulis keperluan siswa.

Adapun materi yang disampaikan kepada para siswa SMK terkait definisi akuntansi, fungsi akuntansi, siklus akuntansi, contoh bagan alir data dan bagan alur dokumen transaksi akuntansi pencatatan pembelian (pengeluaran Kas). Kegiatan PKM yang berjudul pengenalan sistemn informasi akuntansi aada sisiwa SMK jurusan tehnik computer dan jaringan sebenarnya adalah menyelaraskan kurikulum yang sudah ada terkait mata pelajaran Algoritma dan Pemrograman. Pada pelajaran algoritma dan pemrograman siswa jurusan tehnik computer dan jaringan (TKJ) diajarkan untuk memahami pengunaan tool flowchart dan pengenalan tipe data dalam membuat operating system (OS) pada aplikasi computer. Sehingga sangat sesuai jika materi yang didapatkan disekolah diperkaya dengan referensi keilmuan terkait pembuatan operating system program informasi akuntansi. (Fery:2015)

Pentingnya memahami dasar-dasar sisitem infromasi akuntansi bagi para siswa sebagai bekal ilmu apabila siswa akan melanjutkan pendidikan ke jenjang akademik atau universitas. Apalagi jika siswa akan melanjutkan ke jurusan tehnik informatika computer, siswa sudah memiliki referensi keilmuan terkait aplikasi dan jaringan computer untuk membuat dan merancang aplikasi informasi akuntansi. 


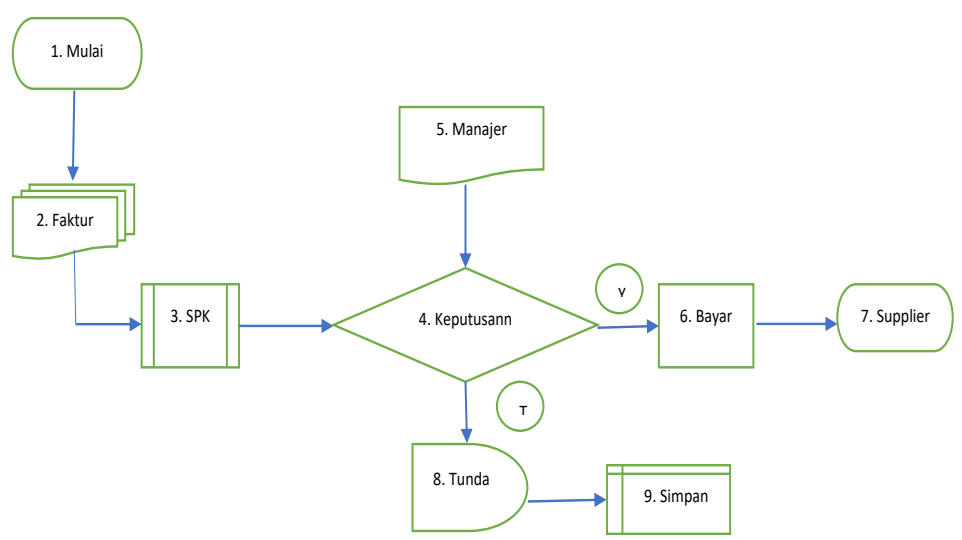

Gambar 2. Rancangan aplikasi informasi akuntansi

\section{KESIMPULAN}

Hasil pelaksanaan kegiatan PKM menghasilkan kesimpulan bahwa para siswa SMK NUFA Citra Mandiri Jurusan Tehnik Komputer dan Jaringan Kelurahan Kedaung, Sawangan Depok cukup antusias dalam mengikuti kegiatan PKM, terutama terkait materi sisitem informasi akuntansi yang dijabarkan narasumber.

Selain itu, kegiatan PKM ini bertujuan memberikan pemahaman dan pengenalan sisitem informasi akuntansi dan merupakan bentuk penyelerasan mata pelajaran algoritma dan pemrograman dimana para siswa mendapatkan pengenalan tentang fungsi bagan alir dan type data. Dan pada pengayaan materi kegiatan PKM kali ini siswa diajarkan bagan alir dan type data dari pencatatan transaksi akuntansi pengeluaran kas. PKM yang dilaksanakan merupakan kerjasama dosen prodi S1 Akuntansi Universitas Pamulang dengan Yayasan Nurul Falah dan SMK NUFA Citra Mandiri kelurahan Kedaung, kecamatan Sawangan, Kota Depok, terlaksana dengan masih amat banyaknya kekurangan dan keterbatasan, kami menyarankan untuk PKM selanjutnya, pengenalan dasar-dasar system infromasi akuntansi ini melibatkan tidak hanya dosen dari Prodi Akuntansi dan Bisnis namun juga bias bersinergi dengan dosen dari Prodi Tehnik Informatika dan Komputer, sehingga dapat menyelaraskan tujuan dan gambaran lebih jelas pembuatan aplikasi jaringan computer akuntansi

\section{REFERENSI}

Harahap, Sofyan S. Teori Akuntansi. (Edisi Revisi 2011). Rajawali Press. PT. Raja Grafindo Persada. Haryadi, R. N., Yusup, A. M., Utarinda, D., Mustika, I. A., Sandra, D., \& Rokhmawati, D. U. (2022). Sosialisasi Penggunaan Aplikasi E-Learning Berbasis Website di Masa Pandemi Covid-19. BEMAS: Jurnal Bermasyarakat, 2(2), 110-115.

Hermaliani, E. H., Handayani, S., Astria, I., \& Nolanda, R. (2016). Sistem Informasi Akuntansi Pada Outlet Perdagangan SMKN 1 Bogor. Bina Insani ICT Journal, 3(2), 341-349.

Husaini, M. (2017). Pemanfaatan teknologi informasi dalam bidang pendidikan (e-education). MIKROTIK: Jurnal Manajemen Informatika, 2(1).

Mulyadi, Y., Mukhidin, M., Setiawan, A., Hamdani, A., \& Purnawan, P. (2010). Pemetaan SMK Di Jawa Barat, Bangka Belitung dan Kalimantan Tengah. invotec, 6(2).

Sinaga, M. D., Sembiring, N. S. B., Sianturi, C. J. M., \& Ginting, E. (2021). Introduction to MYOB Accounting Basics in Accounting Data Processing at SMK 2 BM Swasta Medan Putri. JUDIMAS, 2(1), 13-22.

Sunarsi, D., et al. (2021). Penyuluhan Wirausaha Untuk Meningkatkan Ekonomi Keluarga Dengan Daur Ulang Barang Bekas Desa Mekarsari Kabupaten Bogor. Jurnal PADMA: Pengabdian Dharma Masyarakat, 1(2).

Yohana Tri Utami, Y. T. U., \& Putri, A. W. S. C. Y. (2019). Game Edukasi Akuntansi sebagai Sarana Peningkatan Minat Belajar Siswa (Studi Kasus: SMK Negeri 8 Bandar Lampung). Game Edukasi Akuntansi Sebagai Sarana Peningkatan Minat Belajar Siswa (Studi Kasus: SMK Negeri 8 Bandar Lampung), 13(2), 16-23. 